\title{
Intervention Class Study to Promote a Morning-Typed Life for Japanese Junior High School Students Using a Picture Leaflet as a Teaching Subject
}

\author{
Misako Kawamata ${ }^{1}$, Ryota Kawasumi ${ }^{1}$, Takahiro Kawada ${ }^{1,2}$, Miyo Nakade ${ }^{3}$, Fujiko Tsuji ${ }^{1,4}$, Milada Krejci ${ }^{4}$, \\ Teruki Noji ${ }^{2}$, Sayako Tsunomori ${ }^{5}$, Hitomi Takeuchi ${ }^{1} \&$ Tetsuo Harada $^{1}$ \\ ${ }^{1}$ Laboratory of Environmental Physiology, Graduate School of Integrated Arts and Sciences, Kochi University, \\ Kochi, Japan \\ ${ }^{2}$ Center for Regional Collaboration, Kochi University, Kochi, Japan \\ ${ }^{3}$ Department of Nutritional Management, Faculty of Health and Nutrition, Tokai-Gakuen University, Aichi, \\ Japan \\ ${ }^{4}$ University of Physical Education and Sport PALESTRA, Prague, Czech Republic \\ ${ }^{5}$ Affiliated Junior High School, Faculty of Education, Kochi University, Kochi, Japan \\ Correspondence: Tetsuo Harada, Laboratory of Environmental Physiology, Graduate School of Integrated Arts \\ and Sciences, Kochi University, Kochi, 780-8520, Japan. E-mail: haratets@kochi-u.ac.jp
}

Received: June 11, 2017

Accepted: July 23, $2017 \quad$ Online Published: August 22, 2017

doi:10.5539/ijps.v9n3p79

URL: http://doi.org/10.5539/ijps.v9n3p79

This study was financially supported by the Research Foundations by Japan Dairy Association (J-MILK) (2013-2014, 2016) (To T. HARADA) and also by Funds from Japan Society for the Promotion of Science (JSPS Grant Number JP 16K01871, 2016-2019: To H. TAKEUCHI).

\begin{abstract}
An intervention study was performed as a class (50 min for 136 junior high school students aged 13-14 years old) using a picture leaflet for junior high school students. The leaflet shows a detailed model day for "morning-typed student" versus "evening-typed one" based on several scientific evidences so far. An integrated questionnaire was administrated just before the intervention class and also one month after the class and the effects of class was evaluated. The questionnaire included the Diurnal Type Scale (DTS) which Torsvall and Ák kerstedt (1980) constructed, and questions on sleep habits, mental health and breakfast contents. Among the students who occupied $75 \%$ as the morning- and medium typed populations before the intervention, students who increased the number of dishes at breakfast after the intervention class did not significantly shift their DTS scores $(p=0.200)$, while students who did not change the number shifted their DTS scores to more evening-typed $(\mathrm{p}=0.012)$. Among ones who occupied $25 \%$ as evening-typed, students who increased the number of dishes significantly shifted their DTS to morning-typed $(\mathrm{p}=0.026)$, while ones who did not change the number did not change their DTS ( $p=0.893$ ). In the whole, although the students experienced the intervention class, there were no significant effects to shift their diurnal rhythm into morning-typed direction, because the month after the intervention is the winter holidays (December-January). The intervention study may be effective for students to prevent the shift of their diurnal rhythm into "evening-typed", even though the teacher of the intervention class has no previous knowledge on sleep sciences at all and study the leaflet for only 2 or 3 hours just before the class.
\end{abstract}

Keywords: intervention class, a picture leaflet, junior high school students, for morning-typed life

\section{Introduction}

Breakfast has been reported to be an important issue for promoting school marks and total health of children as follows.

Recently Japanese elementary school children who had sleep hours generally longer than 9 hours showed clearly higher markings in Japanese language than those who had slept only shorter than 9 hours (Takeuchi et al., 2017). 
A cross-sectional data in Korea were analyzed on a sample of 1,652 high-school seniors (942 males and 710 females) drawn from the 2004 Korea Education Employment Panel. Females who skipped breakfast had a lower probability of having the highest scores in language (OR Z 0.41, p<0.05), mathematics (OR Z 0.24, $<<0.01$ ), or foreign language (OR Z 0.18, $\mathrm{p}<0.01$ ), while males had a lower probability of having the highest scores in language only (OR Z 0.46, p<0.05) (Kang \& Park, 2016). A cross-sectional study has been performed and it consisted of a sample of 1269 children (697 boys and 572 girls) aged 6 years from the Chinese city of Jintan. Results of this study showed that children who regularly have breakfast on a near-daily basis had significantly higher full scale, verbal, and performance IQ test scores (all pb 0.001) compared to children who "sometimes" have breakfast (Liu et al., 2013).

O'Neil et al. (2014) showed the definition and criteria for a quality of breakfast as a role of breakfast in health in USA. According to the "Research Commentary" of this reference, there have been evidences that consumption of a breakfast meal was positively associated with general health and well being for both adults and children, suggesting the need to elevate the importance of breakfast in dietary guidance and nutrition education and communications.

For children in the world, breakfast skipping problems are serious and several studies have been performed on the problem so far. For promoting taking nutritionally rich breakfast for children, attitudes, parental descriptive norms and clustering at school level are reported to be important and also related to breakfast skipping (Moor et al., 2009). In this study, participants were 1672 with $5^{\text {th }}$ and $6^{\text {th }}$ grade of elementary school pupils within 52 schools in 9 local education authorities across North, South and West Wales. In multivariate ordinal logistic regression analyses, adjusted for clustering at the school-level, only attitudes towards breakfast, parental descriptive norms and self-efficacy for eating breakfast were significantly associated with breakfast skipping (Moor et al., 2009).

An effective method for children to have breakfast with full nutritional staffs seems to be supplying breakfast. The projects as "supplying breakfast" have been performed so far as follows. In USA, a School Breakfast Program (SBP) was performed for cognitive achievement (Frisvold, 2015). The SBP is a federal entitlement program that offers breakfast to any student, including free breakfast for any low-income student, who attends a school that participates in the program. Using the details of these mandates as a source of identifying variation, it was found that the availability of the program increased student cognitive achievement. On the other hand, as an breakfast supplying program in South Africa, an evaluation included a three-phase approach to establish a baseline of learners in relation to performance and nutritional status; an interim phase; and final phase to ascertain any changes after the introduction of the breakfast programme. Triangulation of the anthropometric and qualitative research suggests that children benefitted from the public-private social investment scheme (Hochfeld et al., 2016).

Online education program was performed and it was effective in comparison with in-person education for increased frequency to take breakfast for children to examine the influences of online and in-person group nutrition education on changes in knowledge, attitudes, and behaviors related to breakfast eating (Au et al., 2016). Increases in the frequency of eating breakfast were greater for both the parents $(\mathrm{P}=0.0007)$ and child $(\mathrm{P}=0.01)$ in the online group education group compared with the in-person group education during the same time points. However, whether the in-person education using a specific teaching material is effective or not for the promotion for children to get breakfast with full nutrition is not clear currently, because there have been no intervention studies of in-person education with a specific teaching materials in relation with a diurnal rhythm, sleep health and breakfast importance.

Tryptophan included in proteins taken at breakfast seems to become resource for morning synthesize of serotonin in the morning based on the resent research (Harada et al., 2007). Serotonin can be affective for promoting mental health and also can be an inner zeitgeber for circadian clocks of human (Nakade et al., 2009, 2012). The serotonin can be synthesized into melatonin at night in pineal which promote fall-in-sleep at night: Protein which was consumed at breakfast could be effective for promoting the mental health through another synthesis from thyroxin and phenylalanine into dopamine in Japanese infants (Akimitsu et al., 2013). Consumption of cows' milk at morning can promote the shifting of the diurnal rhythms of infants and university athletes into morning-typed persons and promote their sleep health (Takeuchi et al., 2014; Harada et al., 2016; Kawada et al., 2016a, 2016b).

A direct teaching material like as a picture book for promoting "morning-typed life and taking nutritionally rich breakfast" might be effective also for junior high school students. However, there have been no such teaching materials for junior high school students so far. The hypothesis can be tested in this study that such the direct 
teaching material as "picture leaflet" can promote the morning-typed life style to junior high school students even by once class lecture using this leaflet, even though the teacher doing the lecture of the intervention class has no previous knowledge on sleep sciences at all and study the leaflet for only 2 or 3 hours just before the class. The purpose of this study is to clarify whether this hypothesis is true or not.

More over there have been intervention studies on the educational effects of the direct and familiar teaching materials to junior high school students for promoting the health of them through morning consumption of cows' milk and following morning-typed life style. In this study, a teaching material as a picture leaflet for junior high school students was made, and the educational effectiveness of the leaflet was examined on the junior high school students who attended a junior high school affiliated to Faculty of Education, Kochi University. The title of the picture leaflet is "A picture book on diurnal rhythm! Let's take cows' milk at breakfast and become a morning-typed person!" (Asagyunyu no susume: in Japanese).

\section{Participants}

Participants in this intervention class study are 139 (females: 69, males: 70) second grade students attending junior high school affiliated to Faculty of Education, Kochi University. They are members of four "regular classes" (about 35 students per one class). At entrance to this school, students attending this school affiliated to Kochi University have been selected from view point of academic achievements. They and their parents have agreed with the participation in some research works during their junior high school days.

\section{Methods}

\subsection{Research Design}

One intervention class for 50 min was performed by one of authors (RK) who is under graduate student at the $4^{\text {th }}$ grade, Faculty of Education, Kochi University, compulsory schools science teachers training course. The same class with contents using the picture leaflet (Appendixes 1 and 2) as a teaching material was performed to the 4 regular classes (almost same number of females and males) in $14^{\text {th }}$ and $17^{\text {th }}$ December 2017. The contents of the intervention class followed the picture leaflet for junior high students (Appendixes 1,2). The teacher of the intervention class had almost no knowledge on sleep sciences and chronobiology, and he have read and studied contents of the picture leaflet for 2 or 3 hours only and taught it the 4 intervention classes.

\subsection{Measures}

Effects of the intervention class were evaluated by comparing the results of questionnaire studies before, just after and 1 month after the class. For two questionnaire studies just before and one month after the class, an integrated questionnaire (Harada et al., 1998) was used. Just after the classes on $14^{\text {th }}$ and $17^{\text {th }}$ December 2017 , questions on the contents of the picture leaflet were administered to the 4 classes members. The integrated questionnaire included questions on sleep habits (Harada et al., 1998), the Diurnal Type Scale (DTS) which Torsvall and Ákerstedt (1980) constructed, breakfast contents, and the knowledge of the terms and meaning of two physiological substances, "serotonin" and "melatonin". The integrated questionnaire was administered two times, one on $8^{\text {th }}-10^{\text {th }}$ November before the intervention class $\left(14^{\text {th }}\right.$ and $17^{\text {th }}$ December 2016$)$ and another on $11^{\text {th }}$ and $12^{\text {th }}$ January 2017 . The questionnaire on the understanding of the contents of the leaflet (for example the knowledge of "serotonin" and "melatonin") was administered to the participants three times, just before, just after and one month after the intervention.

\subsection{Statistics Analysis}

Results of this study were analyzed with statistical software as SPSS 24 version (22.0 J for Windows; SPSS Inc., Chicago, IL, USA). Wilcoxon pair-wised test and McNemar test were exclusively used for the comparative analysis between data just before the intervention and just after that (or one month later after that), and between just after and one month after the intervention class.

\subsection{Ethic Treatments}

The study followed the guidelines established by the Chronobiology International Journal for the conduct of research on human subjects (Portaluppi et al., 2010). Before administrating the questionnaires, each participant was given a written explanation that detailed the concepts and purposes of the study and stated that their answers would be used only for academic purposes. After the above explanation, all participants agreed completely with the proposal. The study was permitted by the teachers' committee in the junior high school affiliated to Faculty of Education, Kochi University including an ethic examination function. It was also permitted by the ethic committee in the Laboratory of Environmental Physiology, Graduate School of Integrated Arts and Sciences, Kochi University which had carried out an ethical inspection of the contents of the questionnaire. 


\section{Results}

One month after the intervention class, the Diurnal Type Scale (DTS) of the junior high students tended to be increased (Wilcoxon test: $\mathrm{z}=-1.52, \mathrm{p}=0.128$ ) in comparison with the DTS before the class (Figure 1). The intervention class was performed to the four class-rooms (A-D) of the junior high students in a same manner. The contents of the class were based on the contents of the new leaflet (Appendixes 1 and 2). After one month, the rate of students who took cows' milk at breakfast was significantly increased only one among the four class rooms (A class: Wilcoxon test, $\mathrm{z}=1.90, \mathrm{p}=0.058 ; \mathrm{B}: \mathrm{z}=-0.45, \mathrm{p}=0.655 ; \mathrm{C}: \mathrm{z}=-0.65 ; \mathrm{D}: \mathrm{z}=-0.560$ ) compared with that before the intervention classes. However, the analysis on the total data from the four classes showed that the rate of taking cows' milk as $28.3 \%$ was significantly increased to $38.1 \%$ (Figure 2) after the intervention class (McNemar test: $\mathrm{n}=114, \mathrm{p}=0.004$ ).

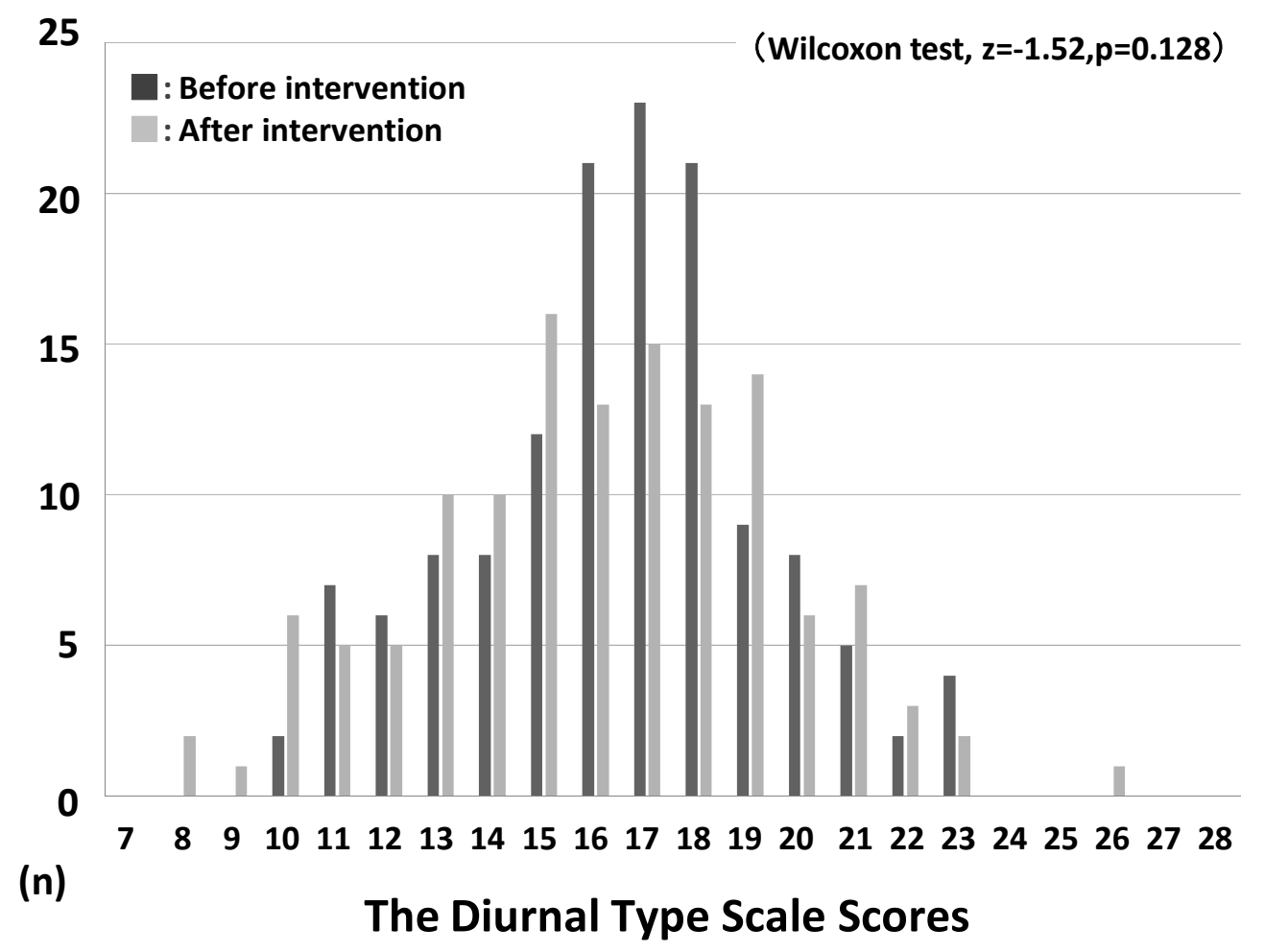

Figure 1. Distribution of the DTS scores of the junior high school students before and one month after the intervention as a class for $50 \mathrm{~min}$. using a picture leaflet 
"Do you have cows' milk usually in the morning?"

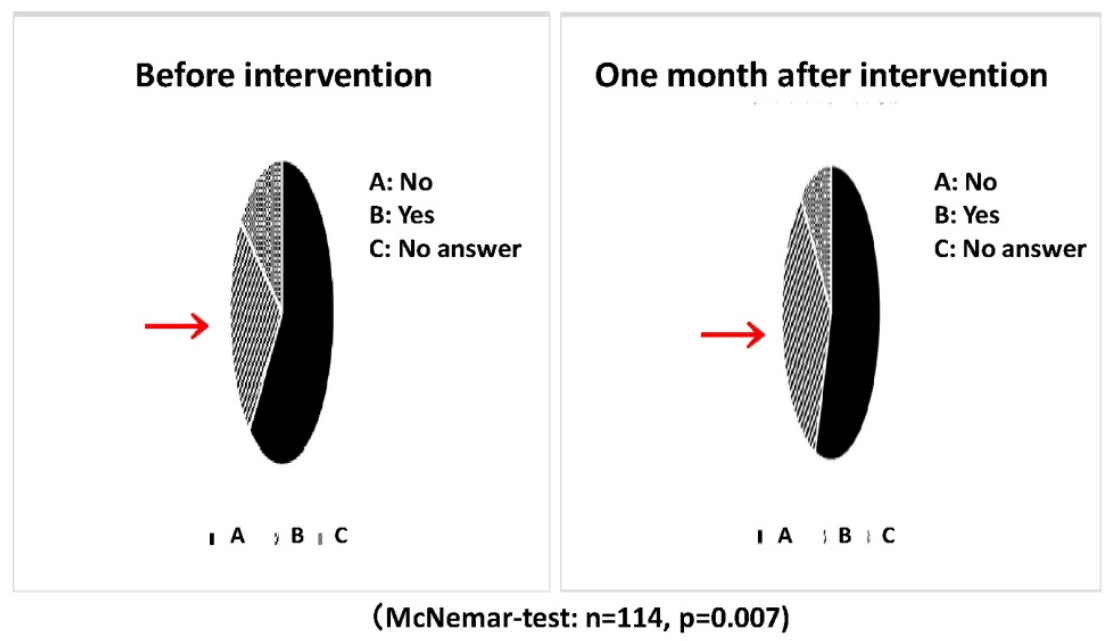

Figure 2. Comparison in the ratio of usual habit to take cows' milk at breakfast between just before the intervention class and one month after it (red arrow shows the ratio of students to take cows' milk at breakfast)

In the intervention classes, the physiological function of "serotonin" as a natural anti-depressor and "melatonin" as a natural sleep pill was explained in the contents of the new leaflet as a teaching material in this study. The knowledge of physiological substance of the serotonin and the melatonin has been fixed in more than $80 \%$ of the students just after the intervention class (Figure 3). However, it has lost and the percentage was decreased into about $20 \%$ during one month after the intervention class $\left(\chi^{2}\right.$-test: $\chi^{2}$-value $\left.=109.098, \mathrm{df}=3, \mathrm{p}<0.001\right)$ (Figure 3 ).

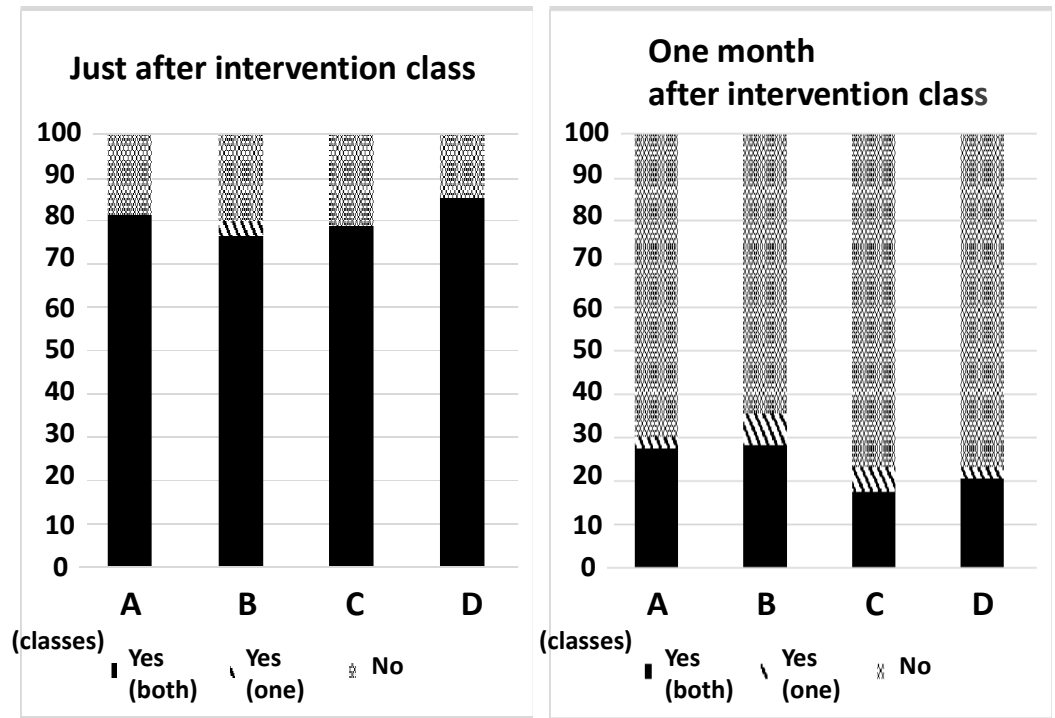

"Do you know the substances of 'serotonin' and 'melatonin' ?"

Figure 3. The knowledge of physiological substance of "serotonin" as a natural anti-depressor and "melatonin" as a natural sleeping pill has lost during one month after the intervention class $\left(\chi^{2}\right.$-test: $\chi^{2}$-value $=109.098, \mathrm{df}=3$, $\mathrm{p}<0.001)$

The effects of the intervention classes were different between the students who occupied the evening-typed 25\% and the other ones who did the $75 \%$ of morning and medium types. The DTS scores before the intervention in the $25 \%$ of students significantly shifted to more morning-typed only in the students who increased the number 
of dishes at breakfast (it meant protein resource was added). On the other hand, the scores shifted to more evening-typed in the students of the $75 \%$, (Table 1 ) only in the students who did neither increased nor decreased the number of dishes at breakfast (Table 1).

Table 1. The relationship between the change in the DTS scores and the change the number of dishes at breakfast in the duration of month from the day just before the intervention class

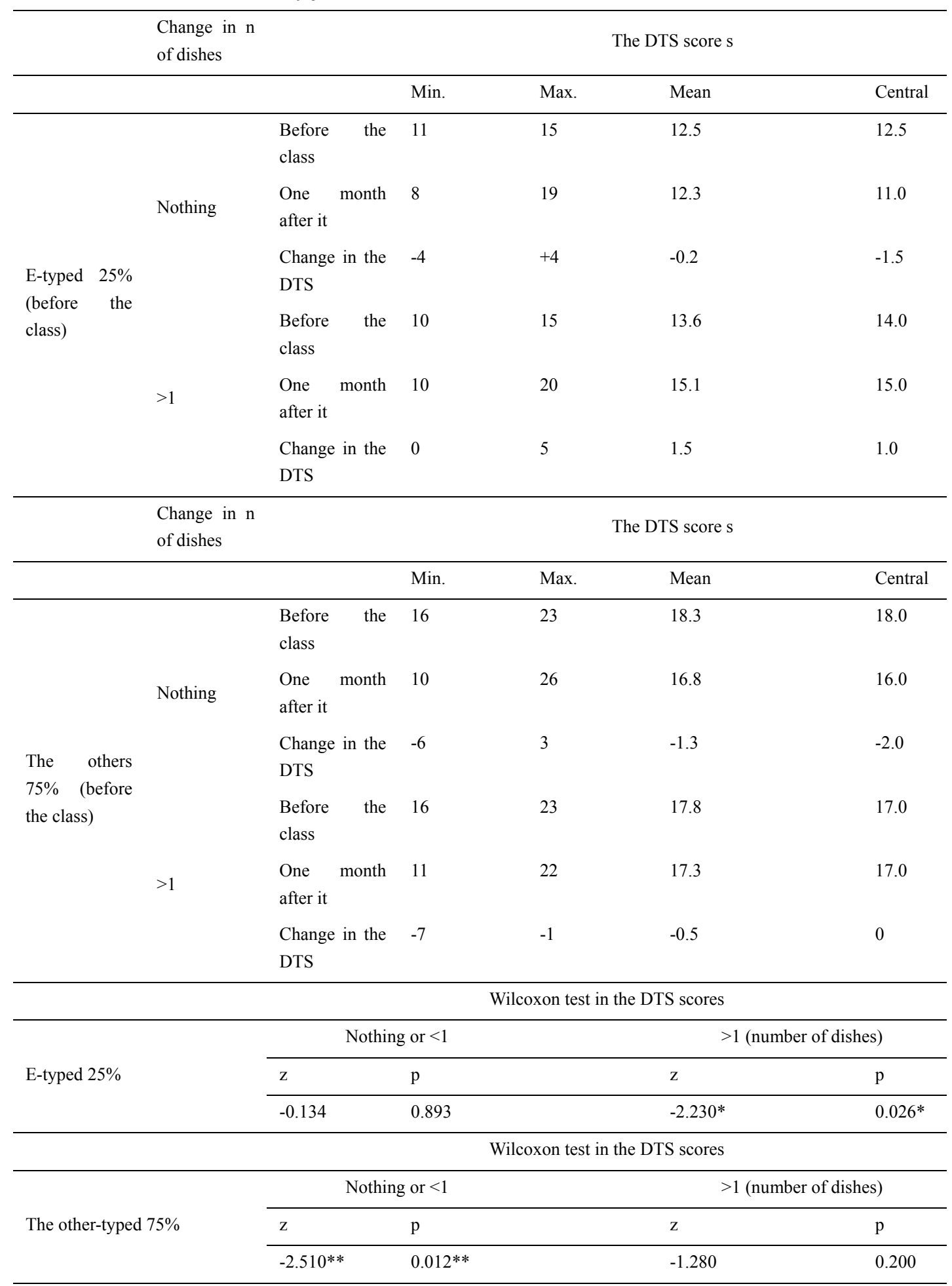

*: The DTS scores were increased as 1 point; **: The DTS scores were decreased as 2 points. 


\section{Discussion}

The intervention class might be effective for students to take cows' milk or protein resources at breakfast which can shift mainly the evening-typed participants of junior high students to more morning-typed ones due to increased amount of synthesis of serotonin which can be "inner-zeitgeber" for the circadian clocks of them, even if the teacher of the new leaflet had no knowledge on sleep sciences and chronobiology and studied the leaflet only for 2 or 3 hours before the class.

This effect could be seen especially in the originally evening-typed students. If they did not drink cows' milk at breakfast even after the intervention classes, the participants shifted to more "evening-typed" persons after one month later from the intervention study. This shift to the evening-typed ones seems to be seasonal effects of shortest day-lengths around "winter-solstice" (especially late sun rise time leading to loss of morning lights) one month after the intervention (late December to early January).

The 24 hour commercialization society is rapidly going on in Japanese society. For example, $98 \%$ of the students attending junior high school affiliated to Faculty of Education, Kochi University has their own smart-phone in 2016 (Tsunomori, Harada et al., unpublished). Kawada et al. (2017) reported that university students who put their own smart-phones in their beds during night sleep were significantly much more evening-typed than those who put it far from their beds. Also in junior high school students, the shifting to more evening-typed life is very dangerous for them to grow in the adolescent days from physical (disturbed menstrual cycles for females adolescents: Takeuchi et al., 2005) and mental view points (higher frequency to be anger, irritated, out-of control of emotion and depressed: Harada et al., 2012). In that meaning, the class using this leaflet and systematic educational occasions on the health education (including educations on nutritional meals, sleep and diurnal rhythms) may be very important for the current compulsory schools education in Japan.

In the future, effective methods can be evaluated to teach the direct teaching material as picture leaflet in one class of $50 \mathrm{~min}$ and longer course which consists of two or three classes (50 $\min \times 2$ or 3). This leaflet consists of three parts: one is the comparison of morning-typed life and evening-typed life, second is the scientific evidences and theoretical basements of well-being by morning-typed life, and third the detailed techniques for children and students to become morning-typed persons. The focus for the evaluation to makes up the best teaching method might be on how the three components can be organized to build up the class.

\section{Conclusion}

In conclusion, the hypothesis in this study was true. The tested hypothesis was that the direct teaching material as "picture leaflet" which has been created in this study can promote the morning-typed life style for junior high school students even by once class lecture using this leaflet, even though the teacher doing the lecture of the intervention class has no previous knowledge on sleep sciences at all and study the leaflet for only 2 or 3 hours just before the class. What is the contribution of this study can be mainly on two points to the professional field on health education. The first one is that the direct teaching material as the picture leaflet could teach the importance of taking protein resource at breakfast to junior high school students, and another point is that this study could make it clear that such direct picture leaflet is powerful for the teachers who are not used to such fields as chronobiology and sleep sciences, to teach junior high school students the importance of morning-typed life and taking breakfast with nutritionally rich menu from view point of heath science.

\section{References}

Akimitsu, O., Wada, K., Taniwaki, N., Krejci, M., Nakade, M., Takeuchi, H., \& Harada, T. (2013). The relationship between consumption of tyrosine and phenylalanine as precursors of catecholamine at breakfast and the circadian typology and mental health in Japanese infants aged 2 to 5 years. Journal of Physiological Anthropology, 32, 13. https://doi.org/10.1186/1880-6805-32-13

$\mathrm{Au}$, L. E., Whaley, S., \& Rosen, N. J. (2016). Online and in-person nutrition education improves breakfast knowledge, attitudes, and behaviors: A randomized trial of participants in the special supplemental nutrition program for women, infants, and children. Journal of the Academy of Nutrition and Dietetics, 116, 450-490. https://doi.org/10.1016/j.jand.2015.10.012

Frisvold, D. E. (2015). Nutrition and cognitive achievement: An evaluation of the school breakfast program. Journal of Public Economics, 124, 91-104. https://doi.org/10.1016/j.jpubeco.2014.12.003

Harada, T., Inoue, M., Takeuchi, H., Watanabe, N., Hamada, M., Kadota, G., \& Yamashita, Y. (1998). Study on diurnal rhythms in the life of Japanese university, junior high and elementary school students including morningness-eveningness preference. In Bulletin of the Faculty of Education, Kochi University Series 1 (Vol. 56, pp. 1-91). (In Japanese) 
Harada, T., Hirotani, M., Maeda, M., Nomura, H., \& Takeuchi, H. (2007). Correlation between breakfast tryptophan content and morningness-eveningness in Japanese infants and students aged 0-15 yrs. Journal of Physiological Anthropology, 26, 201-207. https://doi.org/10.2114/jpa2.26.201

Harada, T., Nakade, M., Wada, K., Kondo, A., Maeda, M., Noji, T., \& Takeuchi, H. (2012). Mental health of children from a chronobiological and epidemiological point of view. In O. V. Rijeka (Ed.), Essential Notes in Psychiatry (Chapter 22, pp. 439-458). Rijeka: Intech. https://doi.org/10.5772/38801

Harada, T., Itani, I., Shirakawa, S., Wada, K., Tsuji, F., Krejci, M., ... Takeuchi, H. (2016). Intervention study using a leaflet entitled three benefits of "Go to bed early! Get up early! and Intake nutritionally rich breakfast!" a message for athletes' to improve the soccer performance of university soccer team. Sleep and Biological Rhythms, 14(sup1), s65-s74.

Hochfield, T., Graham, L., Patel, L., Moodley, J., \& Ross, E. (2016). Does school breakfast make a difference? An evaluation of an in-school breakfast programme in South Africa. International Journal of Educational Development, 51, 1-9. https://doi.org/10.1016/j.ijedudev.2016.07.005

Kawada, T., Takamori, Y., Nakade, M., Tsuji, F., Krejci, M., Noji, T., ... Harada, T. (2016a). Effect of drinking cows' milk at breakfast in promoting sleep-health in Japanese university athletes. International Journal of Psychological Studies, 8, 154-163. https://doi.org/10.5539/ijps.v8n3p154

Kawada, T., Yamazaki, Y., Nakade, M., Noji, Krejci, M., Takeuchi, H., \& Harada, T. (2016b). Questionnaire and intervention study on effects of drinking cows' milk at breakfast on the circadian typology and mental health of Japanese infants aged 1-6 years. Natural Science, 8, 381-396. https://doi.org/10.4236/ns.2016.89042

Kawada, T., Kataoka, T., Tsuji, F., Nakade, M., Krejci, M., Noji, T., ... Harada, T. (2017). The relationship between a night usage mobile phone and sleep habit and the circadian typology of Japanese students aged 18-30 yrs. Psychology, 8, 892-902. https://doi.org/10.4236/psych.2017.86058

Liu, J., Hwang, W.-T., Dickerman, B., \& Compher, C. (2013). Regular breakfast consumption is associated with increased IQ in kindergarten children. Early Human Development, 89, 257-262. https://doi.org/10.1016/j.earlhumdev.2013.01.006

Moore, G. F., Moore, L., \& Murphy, S. (2009). Normative and cognitive correlates of breakfast skipping in 9-11-year-old school children in Wales. Appetite, 53, 332-337. https://doi.org/10.1016/j.appet.2009.07.012

Nakade, M., Takeuchi, H., Taniwaki, N., Noji, T., \& Harada, T. (2009). An integrated effect of protein intake at breakfast and morning exposure to sunlight on the circadian typology in Japanese infants aged 2-6 years. Journal of Physiological Anthropology, 28, 239-245. https://doi.org/10.2114/jpa2.28.239

Nakade, M., Akimitsu, O., Wada, K., Krejci, M., Noji, T., Taniwaki, N., ... Harada, T. (2012). Can breakfast tryptophan and vitamin B6 intake and morning exposure to sunlight promote morning-typology in young children aged 2 to 6 years? Journal of Physiological Anthropology, 31, 11. https://doi.org/10.1186/1880-6805-31-11

O’Neil, C. E., Bredbenner, C. B., Hayes, D., Jana, L., Klinger, S. E., \& Stephenson-Martin, S. (2014). The role of breakfast in health: Definition and criteria for a quality breakfast. Journal of the Academy of Nutrition and Dietetics, 114(Suppl. 3), S8-S26. https://doi.org/10.1016/j.jand.2014.08.022

Portaluppi, F., Smolensky, M. H., \& Touitou, Y. (2010). Effects and methods for biological rhythm research on animals and human beings. Chronobiology International, 27, 1911-1929. https://doi.org/10.3109/07420528.2010.516381

Takeuchi, H., Oishi, T., \& Harada, T. (2005). Association between Morningness-Eveningness preference and mental/physical symptoms in Japanese females 12- to 31 years of age. Chronobiology International, 22, 1055-1068. https://doi.org/10.1080/07420520500398007

Takeuchi, H., Wada, K., Kawasaki, K., Krejci, M., Noji, T., Kawada, T., ... Harada, T. (2014). Effects of cow milk intake at breakfast on the circadian typology and mental health of Japanese infants aged 1-6 years. Psychology, 5, 172-176. https://doi.org/10.4236/psych.2014.52027

Takeuchi, H., Nakao, M., Kurose, W., Kawada, T., Noji, T., Nakade, M., ... Harada, T. (2017). Intervention study to improve meal habit, sleep habit, circadian typology and school marks in Japanese elementary school students. Journal of Sleep and Sleep Disorder Research, 25, 5. 
Torsvall, L., \& Åkerstedt, T. (1980). A diurnal type scale: Construction, consistency and validation in shift work. Scandinavian Journal of Work, Environment \& Health, 6, 283-290. https://doi.org/10.5271/sjweh.2608

\section{Appendixes}

Appendix 1-A: One half of a new leaflet for junior high school students to become more morning-typed ones.
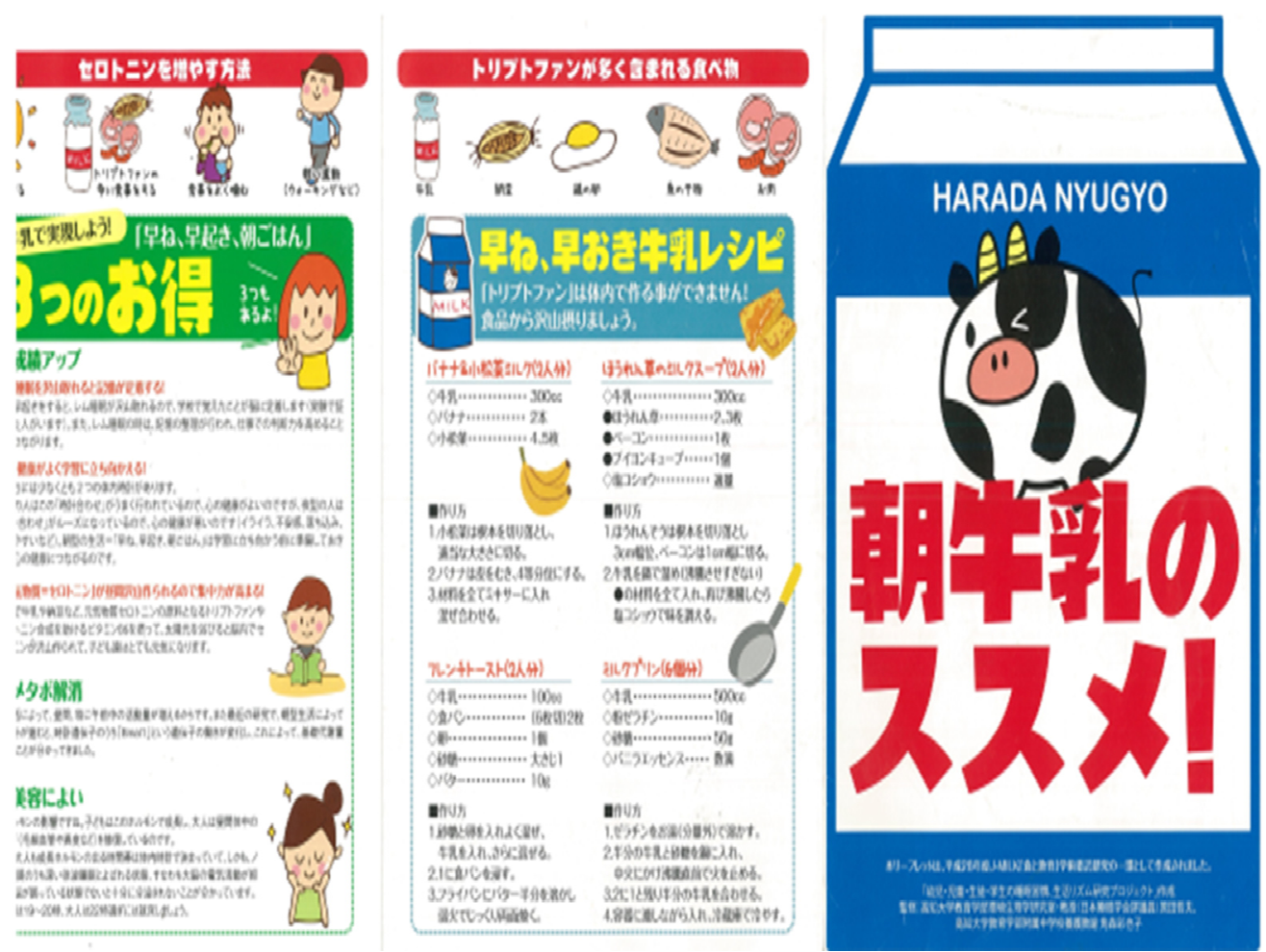
Appendix 1-B: Another half of a new leaflet for junior high school students to become more morning-typed ones.

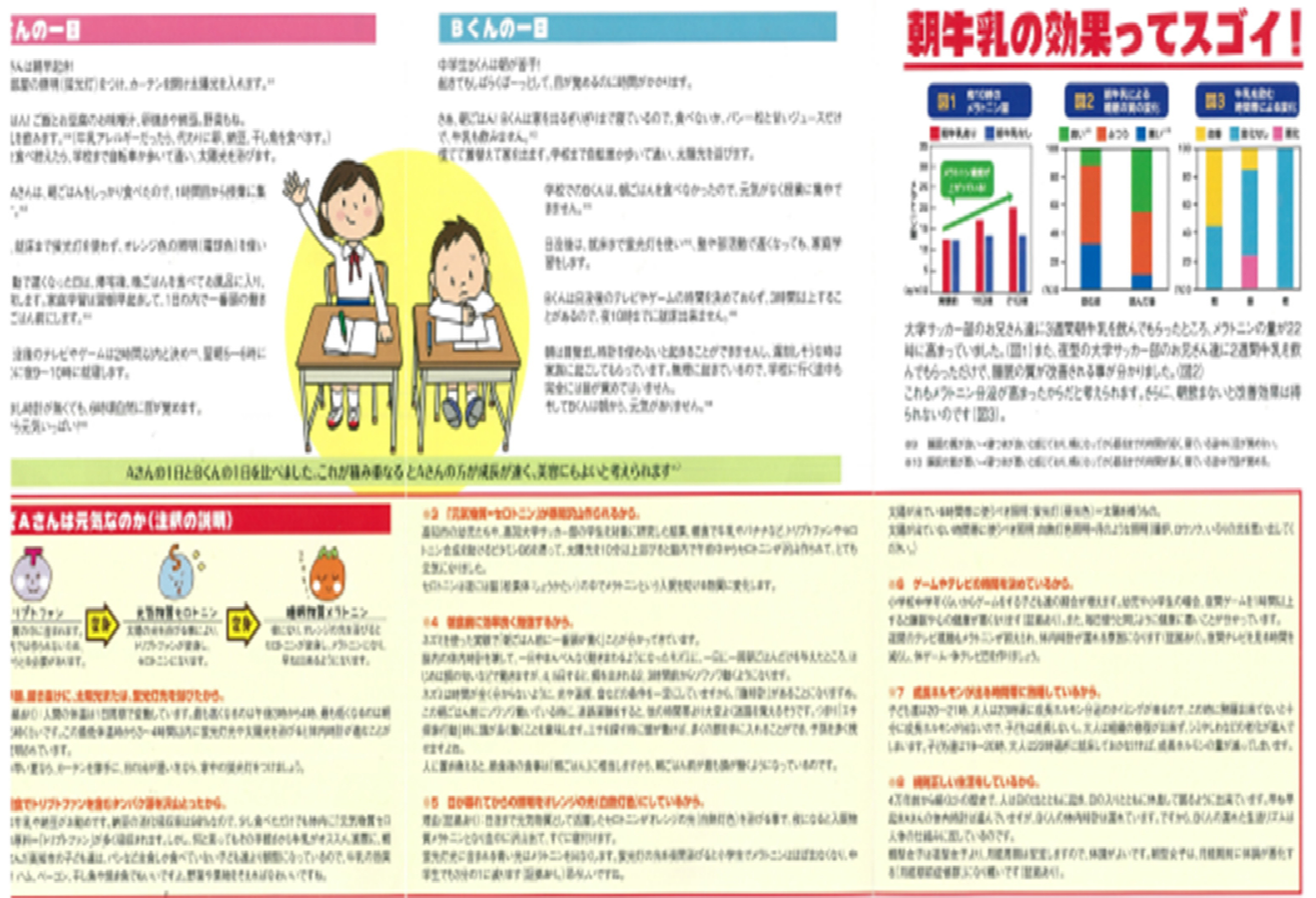

Appendix 2: English version of the picture leaflet used in this study

Title: A picture leaflet for making junior high school students become with morning-typed diurnal rhythm

"Go to bed early and get up early due to drinking a cows' milk in the morning!"

Girl A who is morning-typed junior high school student, get up early in the morning. When she gets up, she opens their curtains and switches on the lightings in her bed room as a fluorescent lamp emitting white lights ${ }^{1)}$.

Let's take breakfast! The Girl A takes nutritionally fruitful breakfast which includes a soy bean soup which has “tofu: fermented soy beans ${ }^{2)}$, cooked chicken-eggs, vegetables and cows' milk ${ }^{2}$.

If you have allergy for the cows' milk you do not need to take it and instead you can other staffs as protein resources like as chicken eggs, ham, sausage, dried fishes and so on. If they have finished to take breakfast, the Girl A leaves their houses and go to junior high school by bicycle or on foot. The Girl A is exposed to sun light ${ }^{3)}$ during going to senior high school. The Girl A can concentrate on the morning classes at school, because she could take nutritionally rich breakfast ${ }^{3)}$.

The Girl A spend her time under the orange-colored lights ${ }^{4}$ from electric bulbs or fluorescent lamps emitting orange-colored lights, after the sun-set at home.

In the days when she come to home late in the evening, she take a bath after the supper, and soon goes to bed. She gets up early in the morning before the breakfast to do her home work during the 1-2 hours before the breakfast, when the psychological concentration is the best during one day ${ }^{5)}$.

The Girl A watches TV and/or plays electronic game in the evening within 2 hours ${ }^{6)}$, she goes to bed 21:00 or 22:007) and get up at 05:00 or 06:00 in the next morning.

The Girl A can wake up naturally (even without waking up items like as ringing watch) at about 6:00. Of course, she is powerful physically and mentally from the morning ${ }^{8)}$.

Boy B who is evening-typed student, is not good at waking up in the morning and being not well physically and mentally in the morning. After getting up, they are not clear with half-sleeping situations. It takes a half hour or more for him to wake up completely physically and mentally. 
Let's take breakfast! The Boy B do not have sufficient time for breakfast and only take one piece of bread and a juice with much sugar ${ }^{2}$, because they have took sleep till very late in the morning.

He does not have cows' milk at breakfast ${ }^{2}$.

He has to hurry up after the poor breakfast to change his cloth and leave his house for the junior high school. He goes to school by bicycle or on foot and is exposed to sun lights. However, this exposure does not lead to the concentration by him in the morning, because he has no protein resources at breakfast ${ }^{3)}$. Therefore he is not powerful physically and mental and cannot concentrate on the classes in the morning because of poor breakfast ${ }^{3}$.

The Boy B spends his time under the white-colored lights ${ }^{4)}$ from fluorescent lamps or LED lamps emitting white-colored lights, after the sun-set at home till the bed time ${ }^{5)}$. Even he comes to home late in the evening due to a private preliminary school for upper school entrance examination ("Jyuku" in Japanese) or sports (or culture) activity after classes, he does his home work in the evening before bed time.

The Boy B watches TV and playing the electric game for so much time more than 3 hours at night and go to bed so late after $22: 00^{6}$.

The Boy B cannot wake up naturally or by themselves, instead he uses items like as ringing watch or asks for his family members to make him awaked in the morning. On the way to school, he is sleepy and do not wake up completely. He is not good at morning physically and mentally ${ }^{8)}$.

Tryptophan: It is included in the protein resource. Tryptophan can be not synthesized in the body, instead it can be absorbed as foods from outside.

Tryptophan can be metabolized to serotonin.

Serotonin (anti-depressor): Serotonin was synthesized from tryptophan after the exposure to sun lights.

Serotonin can be metabolized to melatonin.

Melatonin: In the evening, melatonin was synthesized from serotonin under the orange-colored lights emitted from light bulb or fluorescent lamps emitting orange-colored lights.

1) Because she was exposed to sun lights or fluorescent lamps emitting whit-colored lights, just after the wake-up!

Body temperature fluctuates with 24 hours period. The peak in the temperature is at 15:00-16:00, whereas the bottom is located at 03:00-04:00. Several experiments showed that the exposure to fluorescent lights and sun lights which included the blue lights with $460 \mathrm{~nm}$ of wave length made the phase of the circadian clocks (controlling the body temperature) in advance. In summer when the sun rises early in the morning, let's open the curtain to be exposed to morning sun lights. On the other hand in winter when the sun rises in later morning, let's switch on all fluorescent lamps emitting white lights (including blue lights with $460 \mathrm{~nm}$ of wave length).

2) Because she took sufficient amount of tryptophan which was included in the protein resources at breakfast.

For the breakfast, cows' milk and fermented soy beam ("Natto" in Japanese) can be recommended. Because the rate at which the nutrition of the Natto can be digested and absorbed, is more than $98 \%$, only a small amount of the Natto at breakfast is needed for absorbing an sufficient amount of tryptophan for serotonin. Another recommendation is cows' milk because it is easily taken at breakfast. A epidemiological study showed that children who took only cows' milk at breakfast were morning-typed than those who took only carbohydrates like as bread. A cows' milk should be effective for promotion of the morning-typed life. The protein resources for breakfast can be ham, bacon, dried fishes and cooked fishes. If you can take vegetables and fruits at breakfast, it would be better for your health.

3) Because a sufficient amount of the physiological substance, serotonin as a natural anti-depressor can be made. Several studies on infants in Kochi city and Kochi university soccer athletes implied that the consumption of tryptophan at breakfast and following exposure to sun lights more than $10 \mathrm{~min}$ can promote the serotonin (a natural anti-depressor) synthesis in the brain which leads to be well-being in the morning of the infants and the students especially from mental view point. Serotonin can be synthesized at the pineal of brain to melatonin as a natural sleep pill at night.

4) Because the lightings after sun set which are emitting orange-colored lights with lower color temperature lights were adopted by the Girl A.

Much amount of melatonin in plasma could be synthesized without disturbance of this synthesis by the white-lights exposure (including the physiologically effective blue light with wave length of $460 \mathrm{~nm}$ ). Due to several researches, the exposure to the white-colored lights from fluorescent lamps can depress the plasma 
melatonin to one third for junior high school children and into zero for elementary school children. In the daytime, please use the lightings which emit white-colored lights to support sun lights. At night, please use the lightings which emit orange colored lights (e.g., fire works in the camps and fire places in the houses) to be similar to the lights from the "moon".

(1) Because the Girl A limited the hours for watching TV and playing electric game within 2 hour.

The rate of children who do electric game is increasing from the middle grade of the Japanese elementary school students. If such children attending elementary schools do the electric game usually more than 1 hour every day (in the case of junior high school students more than 2 hours), the sleep health and mental health becomes worse due to doing the game (from research evidence). Due to the research work, the doing the electric game every day can make sleep health and mental health of the children worse. Let's make no-game days for your children! (One day per week) Watching TV at night is possible to depress the amount of melatonin synthesis in children. Therefore, let's make no-TV days for your children! (One day per week).

(2) Because the Girl A slept under 3 or 4 stages in Non-REM, the growth hormone of her was sufficiently secreted into the plasma in early in the evening.

The peak time of day for growth hormone synthesis and secretion into plasma can be at about 20:00-21:00 for children and about at 23:00 for adults. Moreover, during the deep sleep of Non-REM stages (Stages 3-4), increase in growth hormone synthesis can appear in accordance with many evidences by the previous studies. The growth hormone can enhance the growth of children and can repair the damaged tissues of adult body. Therefore, the waking up late in the evening can disturb the growth hormone synthesis and can limit the growth of children. In the case adults, decreased secretion of growth hormone can lead to be bad for skin-care and also can be related to "the aging".

(3) Because the Girl A kept a constant diurnal rhythm with high activity daytime in her life.

Human beings, Homo sapience sapience, developed the diurnal rhythm which shows waking up at the sun rise timing and falling-in-sleep at the sun set timing for the recent 40,000 years. The Girl A keep the advanced phase of circadian clocks and fit the clock phase to the environmental rhythms which have exact 24 hours period, whereas the Boy B has the delayed phase of them and do not fit his phase to the phase of environmental rhythms. That means the diurnal rhythms by the Boy B does not fit to a natural characteristic of human s' circadian clocks. Morning-typed girls have stable menstrual cycles and better-being than evening-typed girls (there is evidence of science study.). Morning-typed girls show moderate or light menstrual-pain and lower frequency to become premenstrual syndrome (PMS) than evening-typed ones.

5) Because he does home work before the breakfast when the psychological activity is at the peak.

A research work using rodents showed that psychological function was on the peak during 2-3 hours after the breakfast. When the biological clocks of the rodents which were located as the Supra Chiastatic Nucleus (SCP) in their brains were destroyed for example by the laser beam, these rodents have become active randomly through the day without their clocks, under the constant conditions. Then, when only breakfast was given to the rodents at the same time as only one time cue under the constant conditions, the rodents move actively responding to the smells from the breakfast during the couple of days at first. However, the rodents began to move two or three hours before the breakfast. This movements previous to the breakfast mean that the rodents have another clocks which relates to breakfast time, in their body. When they were trained to remember the complicated pathways as behavioral and memory experiment, the rodents showed extremely higher scores for the memory of the complicated pathways than the other times of the day. This higher memory function means that the rodents show a higher psychological ability to search foods which appear in a specific time (for example in the morning) of day. When they become functional from psychological view point in occasion of searching foods at a specific time of day, the rodents can collect much foods successfully and also make their children grow up. If it is so also in humans, the psychological function can be at peak in 2 or 3 hours before the time of breakfast.

\section{Three benefits of "Go to bed earlier!, Get up earlier!, and Have a nutritionally rich breakfast!"}

1) Marking in schools becomes higher.

A. Memory which was taken at classes in school can be fixed in the brain of children.

Because they took sufficient REM sleep due to "Going to bed earlier and getting up earlier", children and adults can do arrangement of memories in their brain (e.g., deleting unnecessary memories and unpleasant memories), the ability for adults to make adequate judges in their businesses. 
B. Mental health becomes better and can challenge to do hard work at school.

We have at least two clocks related to diurnal rhythm in our bodies. Morning-typed persons have higher mental health (lower frequency of angry, irritation, out-of-control of emotion, and depression) because the phases of their clocks very well fit to the environmental rhythms which have exact 24 hours cycle and higher amplitudes of the clocks were kept (probably higher secretion of catecholamine like as serotonin in their brains). As a psychological preparation for working hard at school, "Going to bed earlier, Getting up earlier and Taking a nutritionally rich breakfast!" can promote the mental power of children.

C. The psychological concentration becomes higher due to higher serotonin concentration in the body fluid surrounding brain in the morning.

Cows' milk includes much tryptophan as the amino-acid which can be metabolized into serotonin as a natural anti-depressor in the morning. Therefore it is very important for children for well-being with higher mental power in daytime to take a sufficient amount of protein resources and vitamin B6 resource like as banana at breakfast and following exposure to sun lights.

2) Inhibition of obesity and metabolic disorder.

Obesity of metabolic disorder were inhibited by the morning-typed life, because the amount of activity by morning-typed person were higher into 1.5 times than that of evening-typed one. Recent studies showed that a gene "B-MAL1" which is related to circadian clock drive and leads to be increased amount of mitochondria and red-muscles which include much mitochondria and functions as continuous contraction for long duration.

3) Morning-typed life is good for "beauty".

The key is the growth hormone. This hormone promotes the growth of children and repairs the damaged tissues (e.g., micro vessels and skin) in the body during night sleep in adults. The timing for secretion of growth hormone can be determined by the circadian clocks as the 20:00-21:00 for children and around 23:00 for adults. The growth hormone can be secreted only when children and adults are under deep sleep (stages 3 or 4 ) of Non-REM sleep (there have been several evidences so far).

\section{The methods for increasing the amount of serotonin which is synthesized}

1) Breakfast including protein resources (cows' milk, fermented soy bean, ham, eggs, dried fishes so on)

2) Exposure to sun-lights after the breakfast

3) Biting frequently foods at breakfast

4) Morning exercise like as walking in the morning

\section{Foods including much amount of protein}

Cows' milk, fermented soy beans (Natto in Japanese), chicken eggs, dried fishes, meats

\section{Menu introduced for breakfast to promote "Go to bed earlier, Get up earlier, and Take a nutritionally rich} breakfast"

1) Juice including cows' milk, banana and Japanese mustard spinach

2) French toast including cows' milk and chicken eggs

3) Soap including cows' milk, bacon and spinach

4) Pudding includes cows' milk

\section{Copyrights}

Copyright for this article is retained by the author(s), with first publication rights granted to the journal.

This is an open-access article distributed under the terms and conditions of the Creative Commons Attribution license (http://creativecommons.org/licenses/by/4.0/). 